\title{
Designing of SPVWM Inverter Controlled System by Using Suitable Architecture of Power Quality Enhancement Device for Driving Mixed Loads
}

\author{
Rakesh Kumar \\ M. Tech. Scholar \\ Corporate Institute of Science And Technology \\ Bhopal, India \\ rakkeer1994@gmail.com
}

\author{
Mr. Anurag Khare \\ Assistant professor \\ Corporate Institute of Science And Technology \\ Bhopal, India \\ anuragkhare143@gmail.com
}

\begin{abstract}
The stability of a power system is the ability of a power system to restore an operating state of equilibrium for a given initial operating condition after it has been subjected to a physical disturbance, most of the variables of the system being limited so that almost the entire system remains intact. Designing of a SPVWM controlled inverter that has to be made available for efficient power supply to the load of different types. The control of inverter has to be designed in order to enhance the system power supply. To achieve this a space vector pulse width modulation technique has been designed which is then used to provide pulses to the three leg inverter. To design a power quality enhancement device with a simplified architecture such that it will accommodate for the reactive power supply along with an improvement in the active power available at the load terminals. Thus it can be drawn from this work that while designing an inverter with SPVWM control strategy the proposed power quality enhancement device can serve the purpose with better results in terms of power and efficiency. This architecture can also be used in hybrid systems thus making it more reliable controlling method. The system designed is also fitted to feed different types of load like nonlinear load, balanced load and unbalanced load.
\end{abstract}

\section{INTRODUCTION}

With the increase of energy demands, it is becoming an inevitable trend to make full use of distributed generations (DGs), since they have substantial advantages such as power loss reduction, greenhouse gas emission reduction, flexible voltage regulation, peak-load shaving, higher power quality, supply reliability enhancement compared with traditional centralized generations.[5-7] Large-scale distributed power supply interconnection makes micro grid, which can be used as a powerful supplement and effective support for large power grid. There is no doubt that this kind of distributed generation interconnection of micro grid will be one of the trends of power system development. It is worth noting that the safe and reliable operation of micro grid with distributed energy is an important prerequisite. However, the micro grid is close to the load and is easily affected by the load. The increase of unbalanced load and nonlinear load will have an impact on the power quality of the whole micro grid. In severe cases, it can lead to the collapse of the micro grid system itself and influence the voltage and frequency of the distribution network.[8]

\section{LITERATURE REVIEW}

Henan Dong et al. [1] Among the issues of accurate power distribution, stability improvement, and harmonic suppression in micro-grid, each has been well studied as an individual, and most of the strategies about these issues aim at one inverter-based micro-grid, hence there is a need to establish a model to achieve these functions as a whole, aiming at a multi-inverter-based micro-grid. This paper proposes a comprehensive strategy which achieves this 
goal successfully; since the output voltage and frequency of micro-grid all consist of fundamental and harmonic components, the strategy contains two parts accordingly. On one hand, a fundamental control strategy is proposed upon the conventional droop control.

Shun Yuan et al. [2] this paper has a great performance on distributing reactive power, regulating and eliminating harmonic components, eliminating negative sequence components and stabilizing output voltage of inverters and frequency, and improving the power quality of multiinverter-based micro grid. the influence of nonlinear and unbalance mixed loads on output voltage of micro source inverters in micro grid, this paper proposes a comprehensive strategy which can be used to accurate power distribution, harmonic suppression, negative sequence voltage component suppression and stability improvement.

YangLi et al. [3] A two-stage optimization method is proposed for optimal distributed generation (DG) planning considering the integration of energy storage in this paper. In the second stage, the multi-objective ant lion optimizer (MOALO) is first applied to obtain the Paretooptimal solutions, and then the 'best' proposed a twostage solution approach for solving compromise solution is identified by calculating the priority memberships of each solution via grey relation projection (GRP) method, while finally, in order to address the uncertain outputs of DGs, energy storage devices are installed whose maximum outputs are determined with the use of chanceconstrained programming.

Guoqing Li et al. [4] this paper the problem of multiobjective optimal power flow (MOPF) is proposed for hybrid AC/DC grids with VSC-HVDC. First, a MOPF model for hybrid AC/DC grids is built to coordinate the economy, voltage deviation and environmental benefits. Then, a two-stage solution approach, incorporating decision analysis into optimization process, is presented to solve the model.

\section{OBJECTIVE}

The work on the inverter control deals with the following main objectives:

- Designing of a SPVWM controlled inverter that has to be made available for efficient power supply to the load of different types. The control of inverter has to be designed in order to enhance the system power supply. To achieve this a space vector pulse width modulation technique has been designed which is then used to provide pulses to the three leg inverter.

- To design a power quality enhancement device with a simplified architecture such that it will accommodate for the reactive power supply along with an improvement in the active power available at the load terminals.

- While designing the above control the precaution should be taken to avoid any sag in the terminal output voltage and also the voltage available at the load terminal

- We need to enhance the system efficiency by using the above mentioned two controls and adjust the different types of load making it reliable system for all load variation.

\section{METHODOLOGY}

The model has been developed in MALAB/SIMULINK environment. This is a high-level matrix/array language with control flow statements, functions, data structures, input/output, and object-oriented programming features. It has following key features:

- High-level language for scientific and engineering computing

- Desktop environment tuned for iterative exploration, design, and problem-solving

- Graphics for visualizing data and tools for creating custom plots

- Apps for curve fitting, data classification, signal analysis, control system tuning, and many other tasks

- Add-on toolboxes for a wide range of engineering and scientific applications

- Tools for building applications with custom user interfaces

- Royalty-free deployment options for sharing MATLAB programs with end users

The modeling of Dual Voltage Source Inverter system is done which is capable of feeding the load with either solar or wind resources depending on the availability thus making the system more reliable.

The voltage source inverter (VSI) is being made to drive mixed loads. The dc storage capacitors system has also 
being modeled in accordance with the VSI. These are connected to grid at the PCC and supplying a nonlinear and unbalanced load. The VSI delivers the available power at distributed energy resource (DER) to grid.

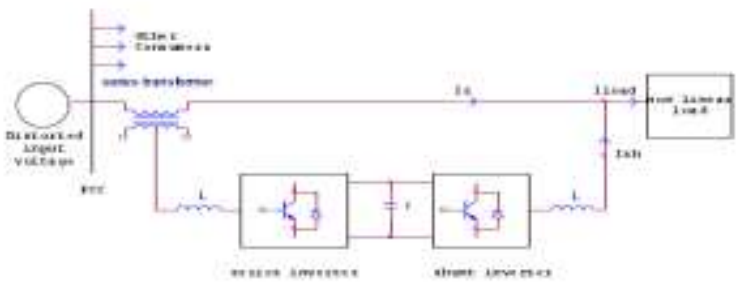

Figure 1 Circuit Diagram of proposed power quality compensation device with load

1) Vector Modulation

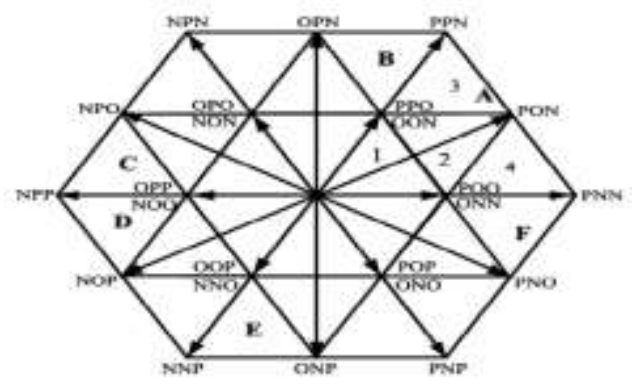

Figure 2 Space-vector diagram of the three-level converter

Assuming the instantaneous voltage value of three-phase sine wave is respectively:

$\mathrm{U}_{\mathrm{a}}=\mathrm{V}_{\mathrm{m}} \operatorname{Sin}(\mathrm{wt})$

$\mathrm{U}_{\mathrm{b}}=\mathrm{V}_{\mathrm{m}} \operatorname{Sin}(\mathrm{wt}-2 \pi / 3)$

$\mathrm{U}_{\mathrm{c}}=\mathrm{V}_{\mathrm{m}} \operatorname{Sin}(\mathrm{wt}+2 \pi / 3)$

The magnitude and angle of the rotating vector can be found as below:

$$
\begin{aligned}
& {\left[\begin{array}{l}
V_{\alpha} \\
V_{\beta}
\end{array}\right]=2 / 3\left[\begin{array}{ccc}
1 & -1 / 2 & -1 / 2 \\
0 & \sqrt{3} / 2 & -\sqrt{3} / 2
\end{array}\right]\left[\begin{array}{l}
U_{a} \\
U_{b} \\
U_{c}
\end{array}\right]} \\
& \overrightarrow{V_{r e f}}=V_{\alpha}+J V_{\beta}=2 / 3\left(U_{a}+a U_{b}+a^{2} U_{o}\right)
\end{aligned}
$$

Where

$a=e^{j 2 \pi / 3}$

$\left|\overrightarrow{V_{r e f}}\right|=\sqrt{V_{\alpha}^{2}+V_{\beta}^{2}}, \theta=\tan ^{-1}\left(V_{\beta} / V_{\alpha}\right)$
If $\theta$ is between $0^{\circ} \leq \theta<60^{\circ}$, then Vref will be in Sector A.

If $\theta$ is between $60^{\circ} \leq \theta<120^{\circ}$, then Vref will be in Sector B.

If $\theta$ is between $120^{\circ} \leq \theta<180^{\circ}$, then Vref will be in Sector C.

If $\theta$ is between $180^{\circ} \leq \theta<240^{\circ}$, then Vref will be Sector D.

If $\theta$ is between $240^{\circ} \leq \theta<300^{\circ}$, then Vref will be Sector E.

If $\theta$ is between $300^{\circ} \leq \theta<360^{\circ}$, then Vref will be Sector $\mathrm{F}$.

The main idea of the simplified algorithm is how to achieve the Calculation Flow based only on one sector instead of six as demonstrated in Fig. 3, just by knowing the relationships in Dwell Time calculations and arrangement for switches between the first sector and the others as explained below:

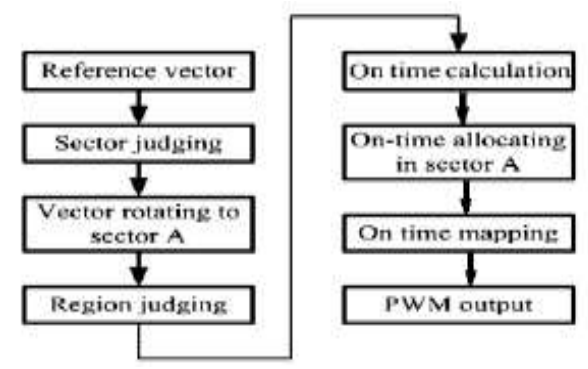

Figure 3 Calculation flow for the three-level SVPWM Simplified calculation

Suppose reference vector a stays in region 2 of sector A, while reference vector $\mathrm{B}$ is obtained by rotating vector a counterclockwise by $60^{\circ}$ as shown in Fig.

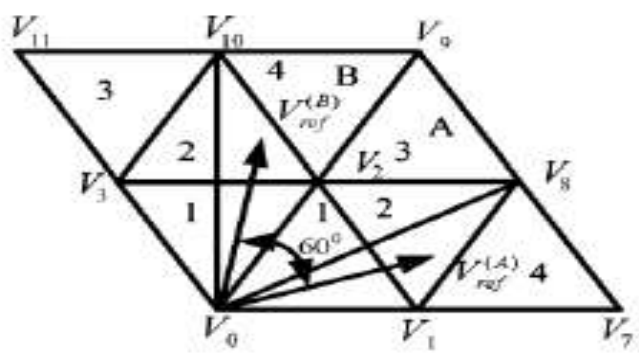

Figure 4. Two vectors with 60 o shifting in the sector A and $\mathrm{B}$. 
So the reference vector $V_{\text {ref }}$ can be expressed in the following form.

$$
V_{r \theta f}^{B}=V_{r \theta f}^{A} * e^{\frac{j \pi}{s}}=2 / 3\left(-U_{b}-U_{c} e^{\frac{j 2 \pi}{8}}-U_{a} e^{\frac{-j 2 \pi}{8}}\right)
$$

And when the reference vector is in the other sectors, it will be rotated to sector $\mathrm{A}$ by $n \pi / 3$ where $(\mathrm{n}=1,2,3,4,5)$. The corresponding reference vector in other sectors can be constructed as given in Table 1 .

Table 1 Relationships Of Voltages Constructing The Reference Vectors In Six Sectors.

\begin{tabular}{|l|l|l|l|}
\hline Sectors & $\begin{array}{l}\text { Phase } \\
\text { Voltage A }\end{array}$ & $\begin{array}{l}\text { Phase } \\
\text { Voltage B }\end{array}$ & $\begin{array}{l}\text { Phase } \\
\text { Voltage C }\end{array}$ \\
\hline A & $\mathrm{U}_{\mathrm{a}}$ & $\mathrm{U}_{\mathrm{b}}$ & $\mathrm{U}_{\mathrm{c}}$ \\
\hline B & $-\mathrm{U}_{\mathrm{b}}$ & $-\mathrm{U}_{\mathrm{c}}$ & $-\mathrm{U}_{\mathrm{a}}$ \\
\hline C & $\mathrm{U}_{\mathrm{c}}$ & $\mathrm{U}_{\mathrm{a}}$ & $\mathrm{U}_{\mathrm{b}}$ \\
\hline D & $-\mathrm{U}_{\mathrm{a}}$ & $-\mathrm{U}_{\mathrm{b}}$ & $-\mathrm{U}_{\mathrm{c}}$ \\
\hline E & $\mathrm{U}_{\mathrm{b}}$ & $\mathrm{U}_{\mathrm{c}}$ & $\mathrm{U}_{\mathrm{a}}$ \\
\hline F & $-\mathrm{U}_{\mathrm{c}}$ & $-\mathrm{U}_{\mathrm{a}}$ & $-\mathrm{U}_{\mathrm{b}}$ \\
\hline
\end{tabular}

Power quality enhancement device Unified Power Quality Conditioner (UPQC) is one of the custom power devices which are used to solve voltage and current related problems simultaneously. The UPQC is able to compensate voltage sag/swell, load current disturbances as well as to compensate voltage interruption and active power transfer to load and source in interconnected system, therefore UPQC help to improve power quality. The operation of UPQC has been evaluated through simulation using MATLAB/SIMULINK software.

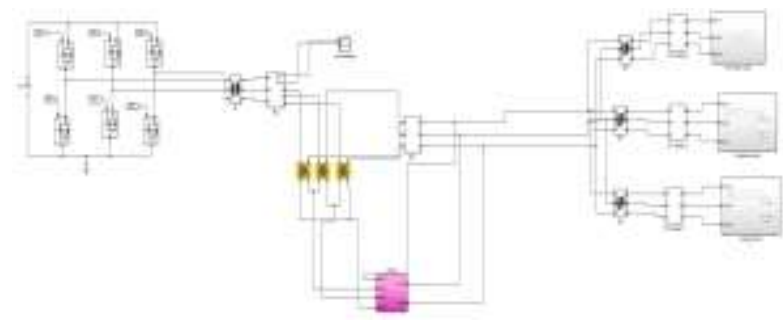

Figure 5 Simulation of the three phase system using UPQC

The performance of the power system is studied for the nonlinear, balanced and unbalanced loads without including the UPQC in the system. Figure 3.2 shows this source connected to the bus BAA2. Feeder lines are connected between the busesB1 and B2. At the bus B1, three different loads are connected. By varying the load, the voltage at bus B2 is studied when the UPQC connected to the system at that bus. The variation of the load may create a voltage sag or swell in the bus B2 depending upon the type of load. This voltage sag and active and reactive power will affect the operation of some other sensitive loads in the system. Figure 3.13 shows the MATLAB simulation diagram of UPQC and implementations. This is designed to maintain the above proposed constraints.

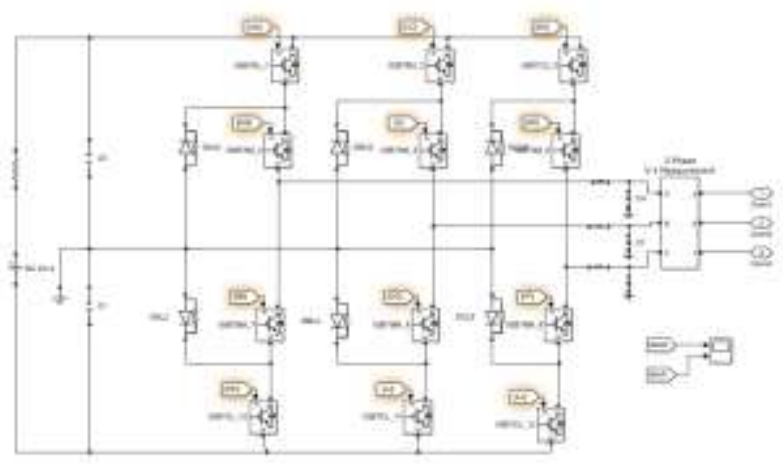

Figure 6 MATLAB architecture of power quality enhancement device

\section{RESULTS}

The analysis of the model has been done in MATLAB/SIMULINK environment. MATLAB combines a desktop environment tuned for iterative analysis and design processes with a programming language that expresses matrix and array mathematics directly. It allows graphical programming to design your system in a simulation environment.

In this work a three leg inverter model has been proposed and a SPWM controller for generating pulses to the inverter. The inverter then converts the DC voltage into three phase output AC voltage. The discrete mode sampling time is kept to be Ts $=1 \times 10^{-6}$. The AC output voltages is then sent to the load. The model can further be integrated with the grid system. In order to overcome the poor and unacceptable performance of the conventional solutions during unsymmetrical loads, an innovative control strategy is anticipated. The proposed strategy is based on transforming the power signals through a power enhancement controller to overcome the deviations. 
The controller used has been designed using 12 IGBTs with specifically designed pulses to be fired to each of them for their operation. Following results are obtained which being summarized in the two cases:

\section{CASE 1: System without Power quality enhancement device.}

CASE 2: System with Power quality enhancement device.

\section{CASE3: Load analysis of two systems.}

This method is a better solution for nonlinear load, and has little effect on unbalanced load. The relationship between amplitudes of the active power oscillations and the reactive power oscillations resulting from unbalanced grid voltage conditions has been deduced.

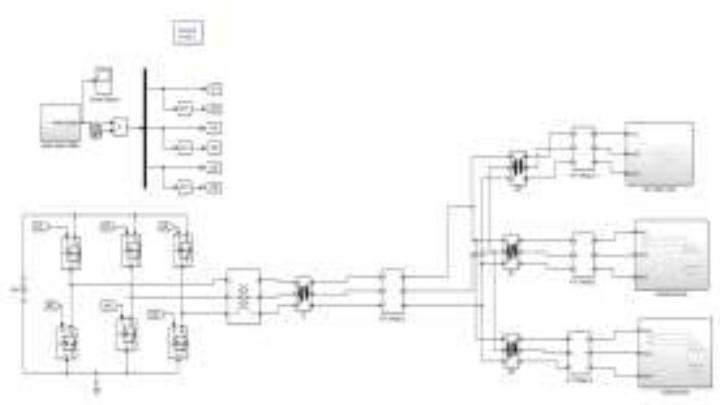

Figure 7 MATLAB/SIMULINK model of system driving loads without power quality enhancement device

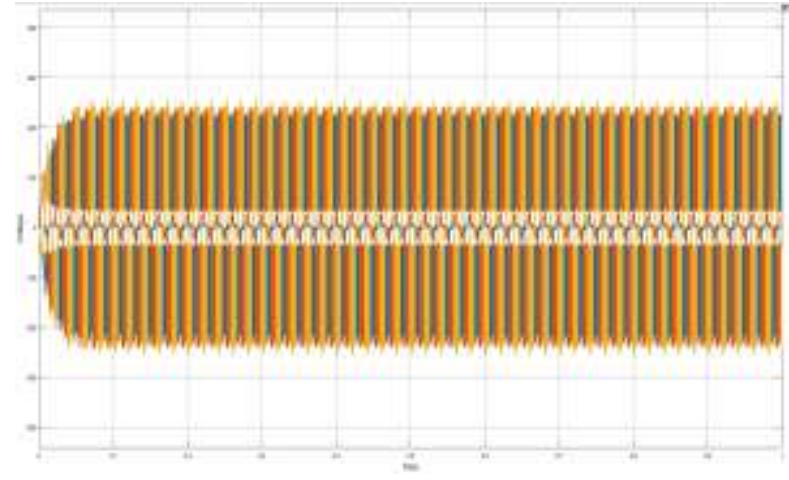

Figure 8 Voltage output from the system without power quality enhancement device

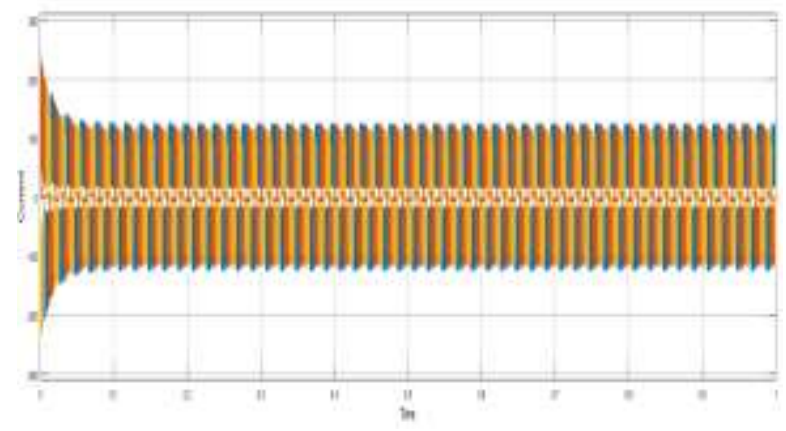

Figure 9 Current output from the system without power quality enhancement device

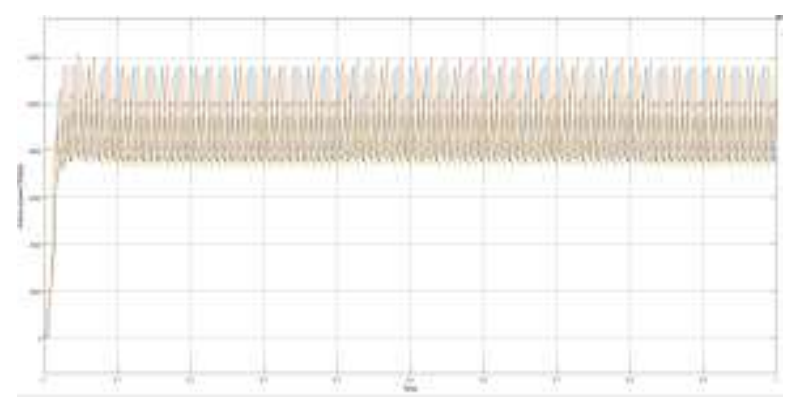

Figure 10 Active power output from the system without power quality enhancement device

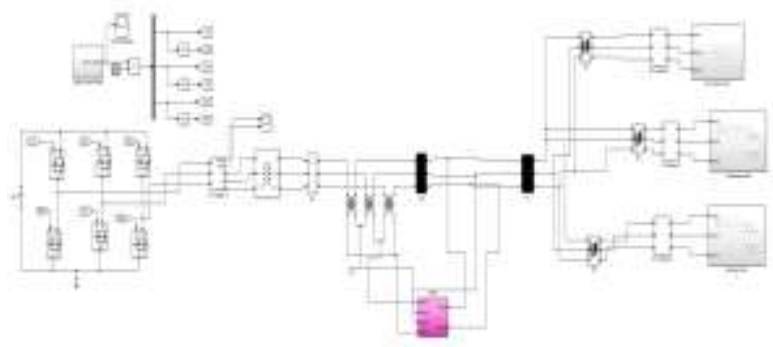

Figure 11 MATLAB/SIMULINK model of system driving loads with power quality enhancement device

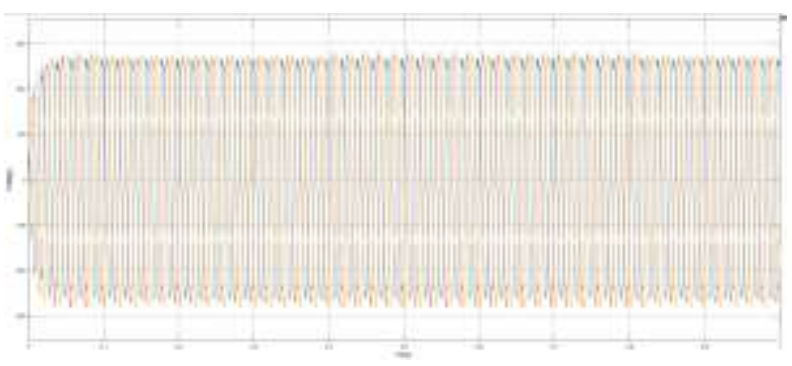

Figure 12 Voltage output from the system with power quality enhancement device 


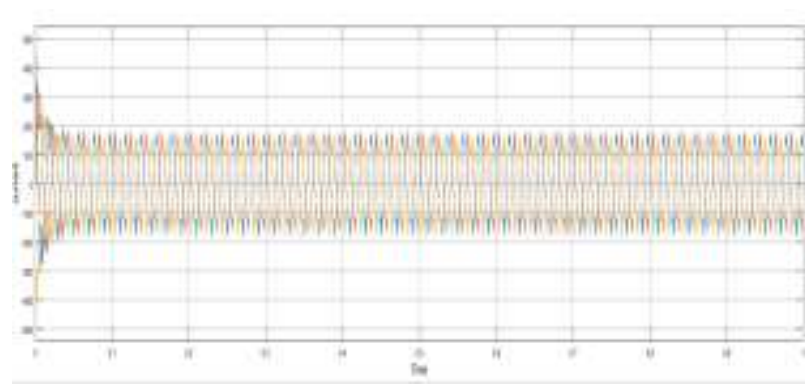

Figure 13 Current output from the system with power quality enhancement device

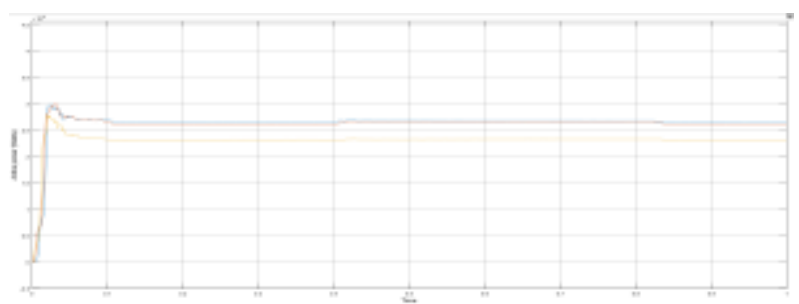

Figure 14 Active Power output from the system with power quality enhancement device

\section{1) Load analysis of the two systems}

\section{a) With Nonlinear load}

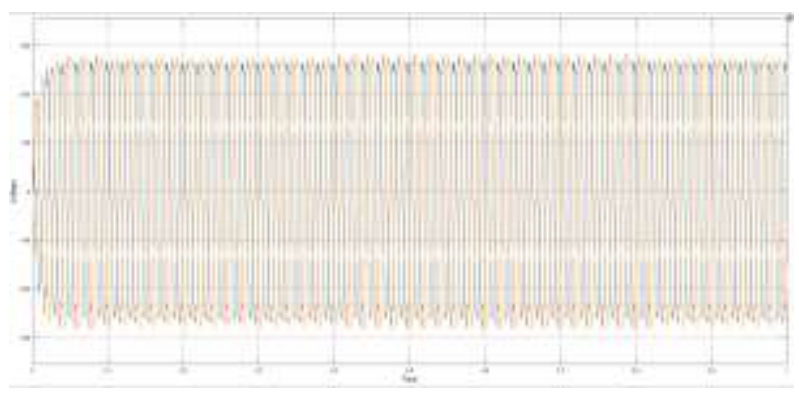

Figure 15 Voltage output of the system with power enhancement device

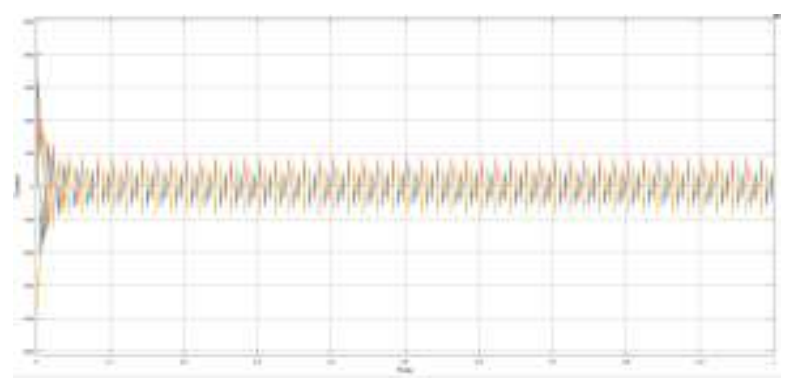

Figure 16 current output of the system with power enhancement device

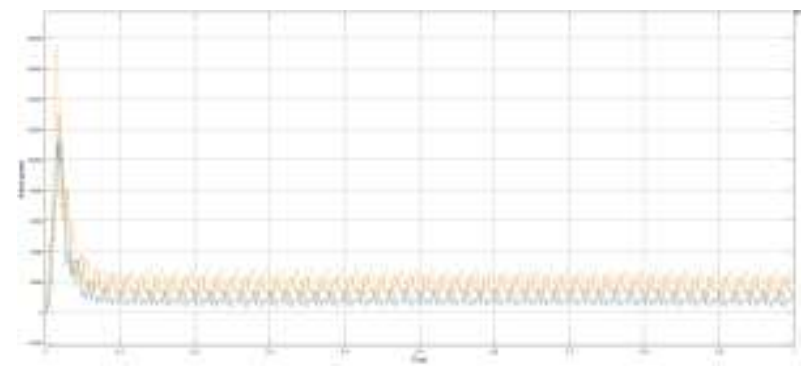

Figure 17 Active Power output of the system with power enhancement device

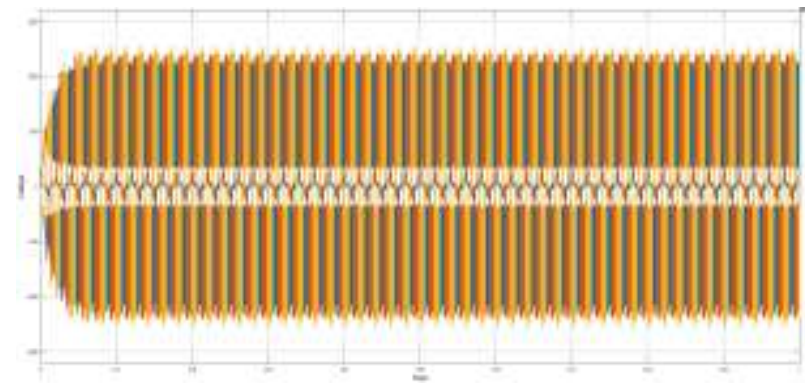

Figure 18 Voltage output of the system without power enhancement device

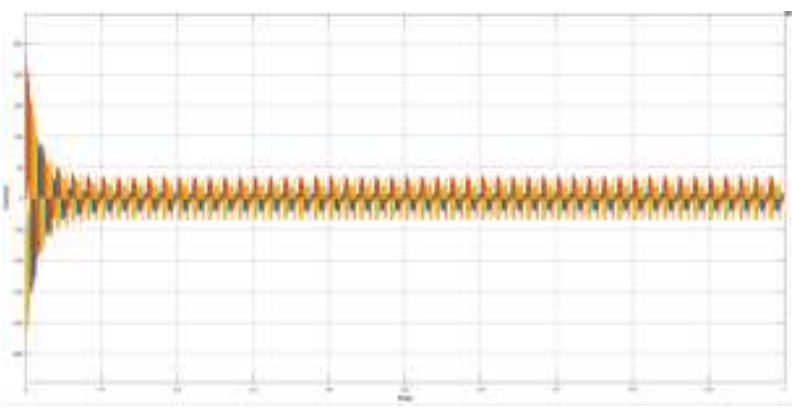

Figure 19 current output of the system without power enhancement device

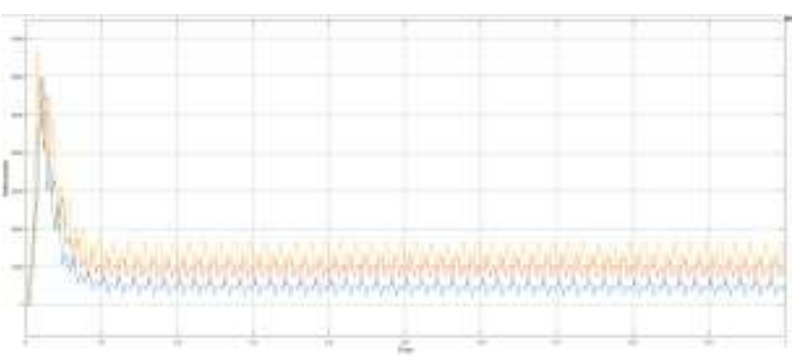

Figure 20 Active Power output of the system without power enhancement device

\section{b) With Unbalanced load}




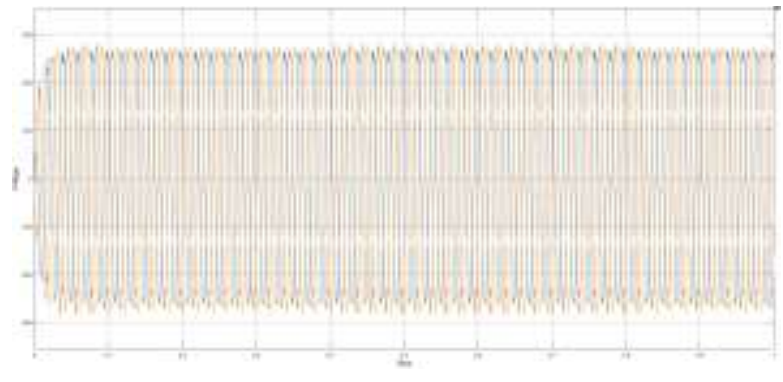

Figure 21 Voltage output of the system with power enhancement device

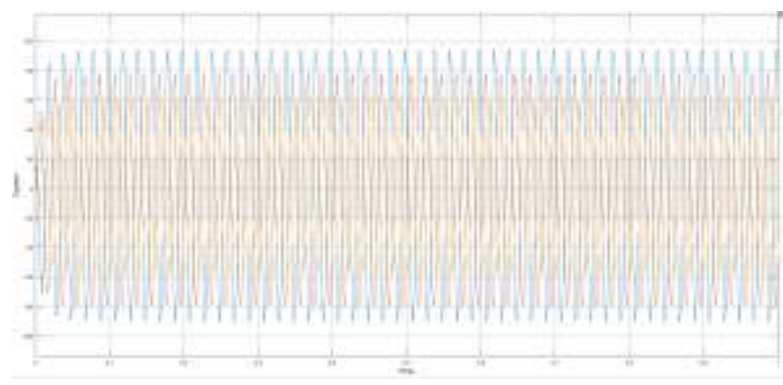

Figure 22 Current output of the system with power enhancement device

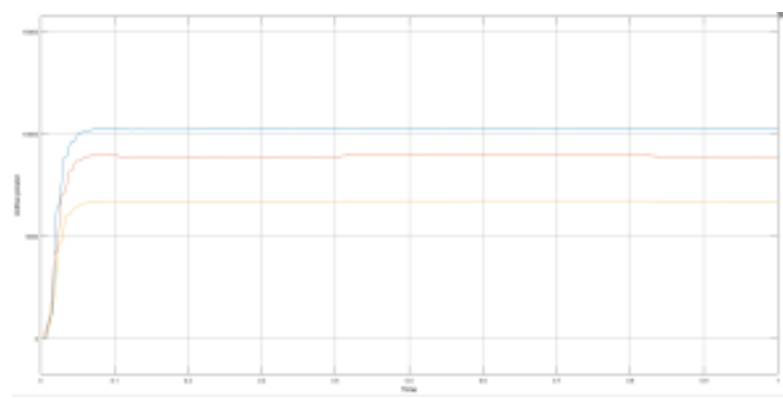

Figure 23 Active Power output of the system with power enhancement device

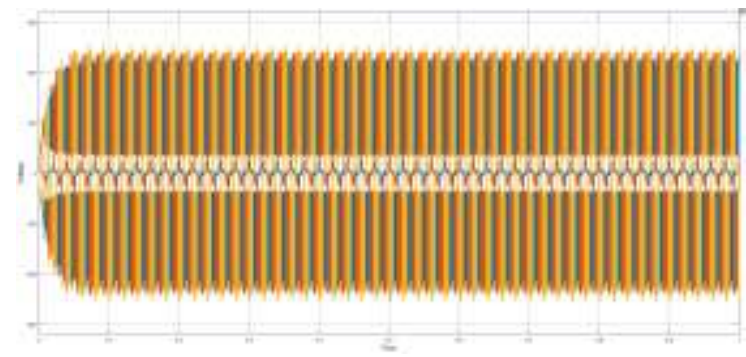

Figure 24 Voltage output of the system without power enhancement device

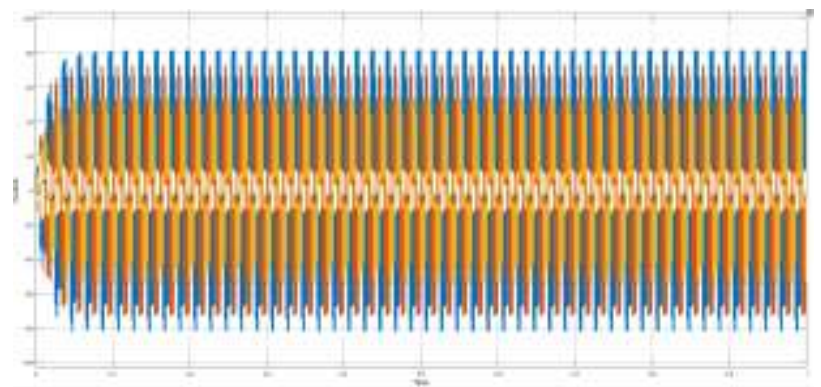

Figure 25 Current output of the system without power enhancement device

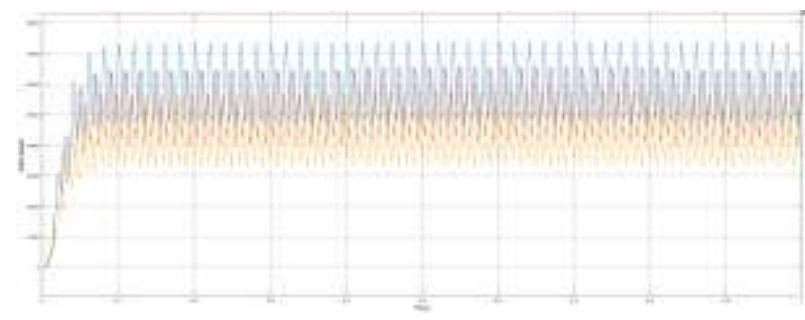

Figure 26 Active power output of the system without power enhancement device

\section{c) With Balanced load}

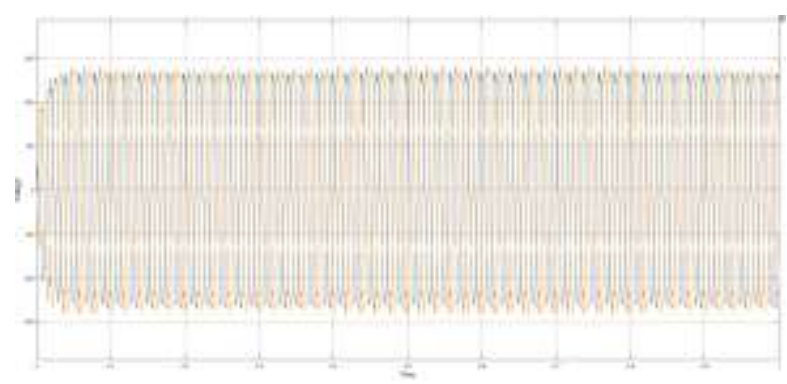

Figure 27 Voltage output of the system with power enhancement device

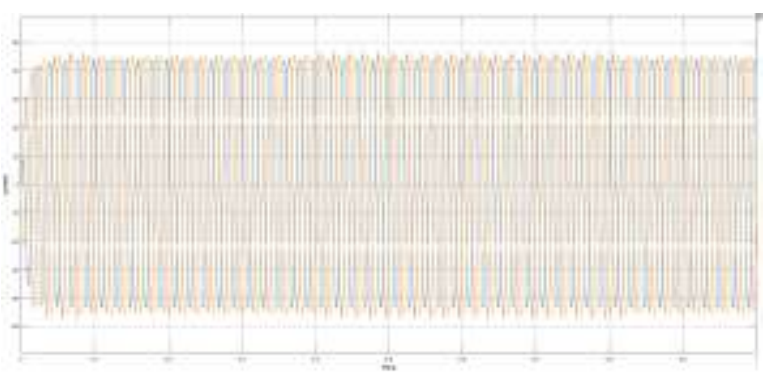

Figure 28 current output of the system with power enhancement device 


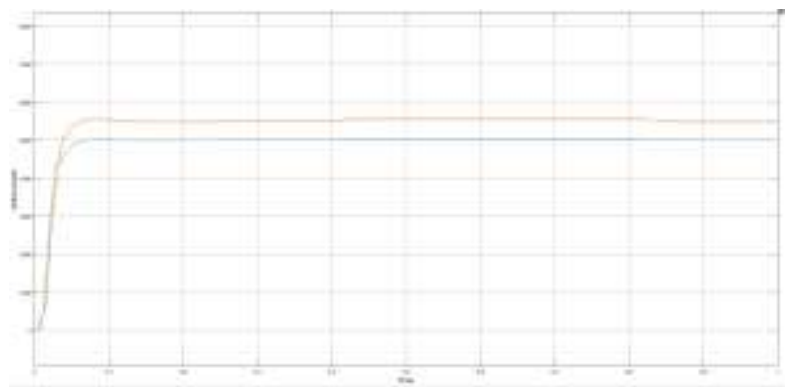

Figure 29 Active Power output of the system with power enhancement device

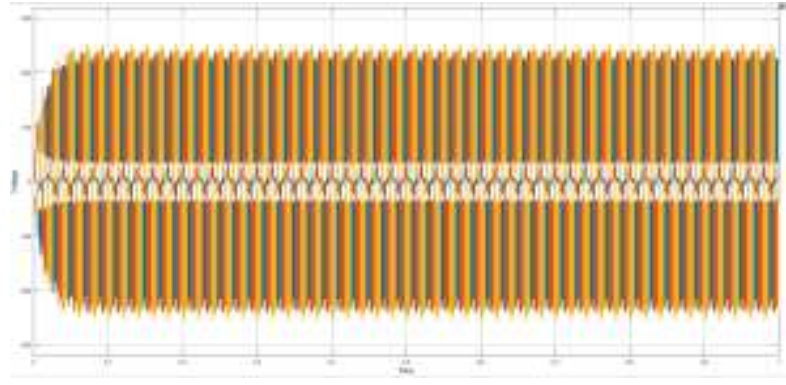

Figure 30 Voltage output of the system without power enhancement device

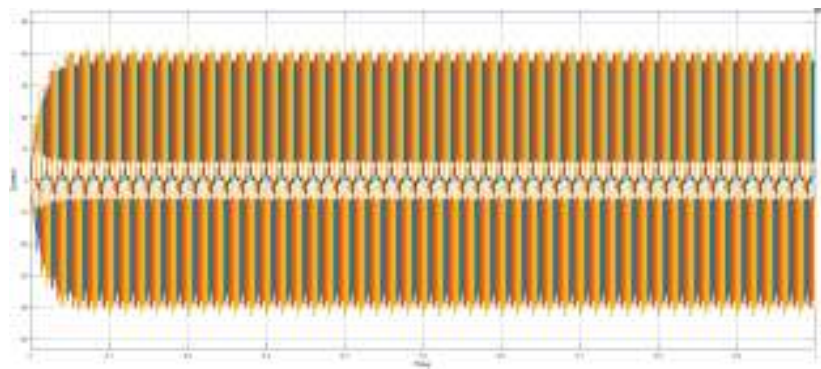

Figure 31 current output of the system without power enhancement device

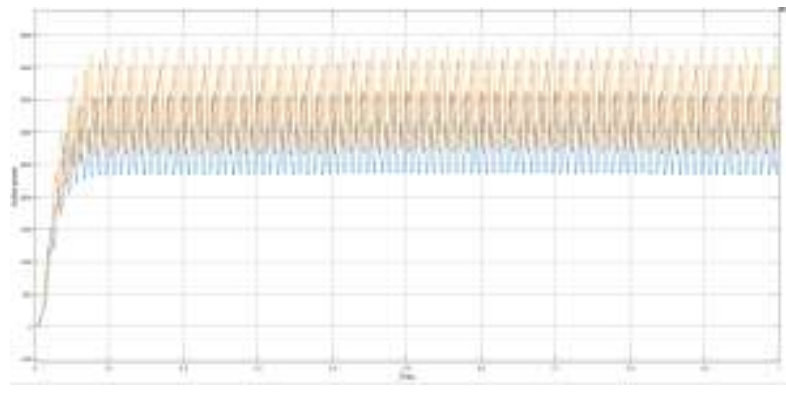

Figure 32 Active power output of the system without power enhancement device

\section{VALIDATION}

In this work the power has been enhanced by using a power quality enhancement device in the system. The systems are made to drive different types of load, nonlinear, unbalanced load and balanced load. The inverter is being driven by using SPWM modulation technique. Explains the enhancement in the power output from the system which will be fed to the loads further. The power quality enhancement device is being made by using a bridge circuit of diodes and IGBBTs

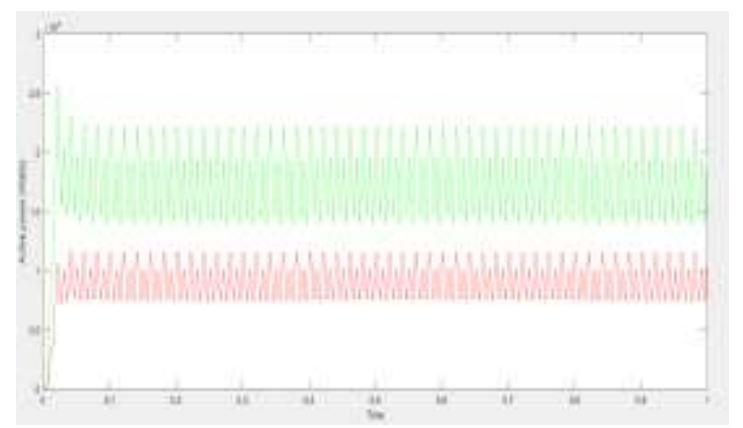

Figure 33 Power Outputs of the system to be fed to the load

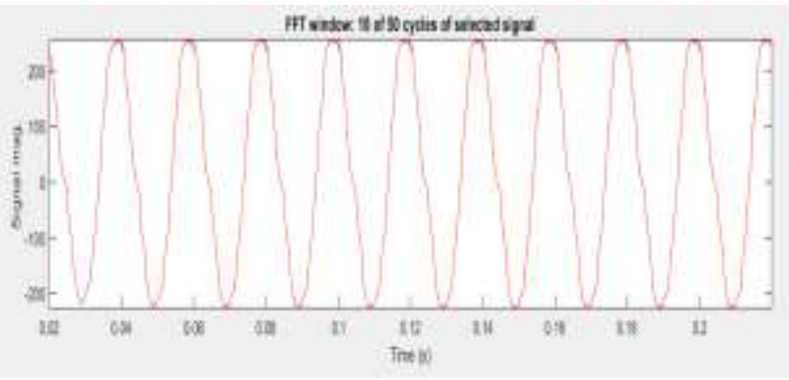

Figure 34 FFT analysis of the voltage output from the system having Power quality enhancement

\section{CONCLUSION}

In order to solve the influence of nonlinear and unbalance mixed loads on output voltage of micro source inverters in microgrid, this paper proposes a comprehensive strategy which can be used to accurate power distribution as well as a power quality enhancement device has been proposed in order to enhance the output power available at the load without any change in the magnitude of the voltage at the load terminal.

Here in this work we have designed a inverter controlled by SVPWM technique along with the power quality enhancement device with a modified architecture in MATLAB/SIMULINK environment and have used it to drive the various loads. 
Further, two models have been created in with we have proposed a model of inverter system driving mixed loads along with power quality enhancement device. The following main conclusions have been drawn from the results.

- On comparing the active power outputs from the system without UPQC controller with proposed power quality enhancement device with a modified architecture, it was found to be that the proposed system gives $29 \mathrm{KW}$ output which is considerably more than the $27.5 \mathrm{KW}$ output of the system without the device. The increase percentage id approximately $5 \%$.

- Also the power outputs at the load terminal has been improved making the system more and more reliable.

- The magnitude of the voltage output is maintained constant while driving the loads

- $\quad$ The UPQC has been compensating supply voltage power quality issues such as sags/swells, unbalance, flicker, harmonics etc.

Thus it can be drawn from this work that while designing an inverter with SVPWM control strategy the proposed power quality enhancement device can serve the purpose with better results in terms of power and efficiency. This architecture can also be used in hybrid systems thus making it more reliable controlling method. The system designed is also fitted to feed different types of load like nonlinear load, balanced load and unbalanced load.

\section{FUTURE SCOPE}

Installing this inverter system along with solar-grid hybrid system will be actually very fruitful because it will reduce the grid dependency. On the other hand, this system promotes green energy which is very important because all the energy sources are depleting day by day. So, people must look for new renewable sources and solar power is definitely one of the best choices in this purpose. In future work an adaptive neural network based control for improved power quality 3 phase grid integrated with nonlinear and linear loads will be designed. The expected control scheme regulates the system voltage and improves the power quality in a very effective manner.

Installing this inverter system along with solar-grid hybrid system will be actually very fruitful because it will reduce the grid dependency. On the other hand, this system promotes green energy which is very important because all the energy sources are depleting day by day. So, people must look for new renewable sources and solar power is definitely one of the best choices in this purpose. In future work an adaptive neural network based control for improved power quality 3 phase grid integrated with nonlinear and linear loads will be designed. The expected control scheme regulates the system voltage and improves the power quality in a very effective manner.

\section{REFERENCES}

[1] Henan Dong, Shun Yuan "A Comprehensive Strategy for Accurate Reactive Power Distribution, Stability Improvement, and Harmonic Suppression of Multi-Inverter-Based Micro-Grid" March 2018 DOI: 10.3390/en11040745

[2] Shun Yuan, Zijiao Han "A Comprehensive Strategy for Power Quality Improvement of Multi-InverterBased Microgrid With Mixed Loads" April 2018 DOI: 10.1109/ACCESS.2018.2826923

[3] Y. Li, B. Feng, G. Li, J. Qi, D. Zhao, Y. Mu, “ Optimal distributed generation planning in active distribution networks considering integration of energy storage," Applied Energy, vol. 210, pp. 10731081,January 2018.

[4] Guoqing Li, Y. Li, et al, "Two-stage multi-objective OPF for AC/DCgrids with VSC-HVDC: Incorporating decisions analysis intooptimization process," Energy, vol. 147, pp. 286-296, 2018.

[5] Andrew Hintz ; RajagopalPrasanna "Comparative study of three-phase grid connected inverter sharing unbalanced three-phase and/or single-phase systems" DOI: 10.1109/ECCE.2015.7310569 Sept. 2015

[6] Emamian. S, Hamzeh. M, Paridari. K, "Robust decentralized voltagecontrol of an islanded microgrid under unbalanced and nonlinear loadconditions," IEEE Trans. International Conference on IndustrialTechnology.pp 1825-1830, 2013.

[7] Paridari. K, Hamzeh M, Emamian S, et al. "A new decentralized voltagecontrol scheme of an autonomous microgrid under unbalanced andnonlinear load conditions," IEEE Trans. International Conference onIndustrial Technology. pp 1812-1817, 2013.

[8] P. Jin, Y. Li, G. Li, Z. Chen, and X. Zhai, “Optimized hierarchical poweroscillations control for distributed generation under unbalancedconditions," Appl. Energy, vol. 194, pp. 343-352, May 2017. 